\title{
Non-steroidal anti-inflammatory drugs and prostaglandin effects on pepsinogen secretion by dispersed human peptic cells
}

\author{
A I Lanas, J Nerín, F Esteva, R Sáinz
}

\begin{abstract}
The effects of aspirin and ibuprofen on pepsinogen secretion were studied in isolated human peptic cells prepared from endoscopically obtained biopsy specimens after collagenase digestion, mechanical disruption, and percoll gradient centrifugation. Pharmacological concentrations of aspirin and ibuprofen $\left(10^{-8}-10^{-4} \mathrm{M}\right)$, potentiated histamine $\left(10^{-6}-10^{-4} \mathrm{M}\right)$ and forskolin $\left(10^{-5} \mathrm{M}\right)$ stimulated pepsinogen secretion without affecting basal secretion, acetylcholine $\left(10^{-6} \mathrm{M}\right)$ stimulated pepsinogen secretion or cell vitality. Augmentation of secretagogue stimulated pepsinogen secretion was dependent on extracellular calcium because potentiation was abolished by calcium depletion of the medium. Cimetidine inhibited the potentiation effect on histamine but not on forskolin stimulated pepsinogen secretion, thus suggesting that this augmentation was independent of histamine $\mathrm{H}_{2}$ receptors. Of interest, potentiation was also independent of endogenous prostaglandin inhibition because exogenous addition of prostaglandin $E_{2}$ and $D_{2}$ increased both basal and acetylcholine stimulated pepsinogen secretion in a dose dependent way, but they did not modify histamine or histamine plus aspirin or ibuprofen stimulated pepsinogen secretion. In conclusion, aspirin and ibuprofen potentiate secretagogue stimulated pepsinogen secretion by dispersed human peptic cells and this might be an additional mechanism of non-steroidal anti-inflammatory drug (NSAID) induced gastric injury. This potentiation effect is regulated by calcium, independent of endogenous prostaglandin inhibition and seems to act on pepsinogen secretion at a post-receptor site.

(Gut 1995; 36: 657-663)
\end{abstract}

Keywords: non-steroidal anti-inflammatory drugs, pepsinogen, prostaglandins.

Effects of aspirin and ibuprofen on basal pepsinogen secretion from dispersed human peptic cells

\begin{tabular}{lllll}
\hline Agent & Number & $10^{-4} M$ & $10^{-6} M$ & $10^{-8} M$ \\
\hline Aspirin & 6 & $-0.05(0.56) \%$ & $+0.66(0.72) \%$ & $+0.68(0.70) \%$ \\
Ibuprofen & 6 & $+0.14(0.20) \%$ & $+0.01(0.25) \%$ & $-0.55(0.27) \%$
\end{tabular}

Pepsinogen released into the medium was expressed as percentage (\%) of the total pepsinogen initially present in cells and secretory responses to stimuli were calculated in the output per un time with basal output subtracted. Basal secretion in these experiments was $5 \cdot 79(0.58) \%$ of total/30 min. Data expressed as mean (SEM).
It is widely accepted that non-steroidal antiinflammatory drug (NSAID) use is associated with a high prevalence of gastroduodenal injury. ${ }^{1}$ It is also recognised that the presence of acid and pepsin enhances the potential damaging effect of these drugs ${ }^{12}$ and, therefore, anti-secretory therapy is commonly prescribed to treat or prevent damage induced by NSAIDs. ${ }^{3}$ The pathogenic mechanisms of NSAID induced gastroduodenal damage remains unclear, ${ }^{12}$ although different mechanisms, most of them related to prostaglandin inhibition, have been proposed. ${ }^{2} 4$

Aspirin and other non-salicylate NSAIDs have been reported to increase or potentiate histamine stimulated acid secretion in vivo ${ }^{56}$ and in vitro in different animal models, ${ }^{7-11}$ suggesting that enhanced gastric acid secretion could play a part in the pathogenesis of NSAID induced gastroduodenal mucosal damage. The mechanisms of NSAID stimulated acid secretion have been extensively explored by Levine et $a l^{7-9}$ in an in vitro rabbit parietal cell model, suggesting that NSAID induced acid secretion is regulated by the presence of calcium and the inhibition of prostaglandins.

Although available information provides sufficient evidence that intramucosal activation of acid proteases, mainly pepsinogens, plays an important part in peptic diseases of the upper gastrointestinal tract, ${ }^{12}$ there are almost no data on the potential effects of NSAIDs on pepsinogen secretion by the stomach. In this study we have examined in vitro the effects of two widely and more commonly used NSAIDs (aspirin and ibuprofen) on pepsinogen secretion by dispersed human peptic cells obtained from endoscopic biopsy specimens.

\section{Methods}

\section{Chemicals}

Chemicals were obtained from the following sources: bovine serum albumin (fraction V), acetylcholine, histamine, cimetidine, aspirin, ibuprofen, forskolin, HEPES, percoll, crystalline porcine pepsinogen, soybean trypsin inhibitor, ethylene glycol tetraacetic acid (EGTA), and glucose from Sigma Chemical (St Louis, MO). Collagenase (type IV) from Worthington Biochemical (Freeholdd, NJ); bovine haemoglobin from Gibco Diagnostics (Madison, WI), and prostaglandin $\mathrm{E}_{2}$ and $\mathrm{D}_{2}$ from Calbiochem (La Jolla, CA). 


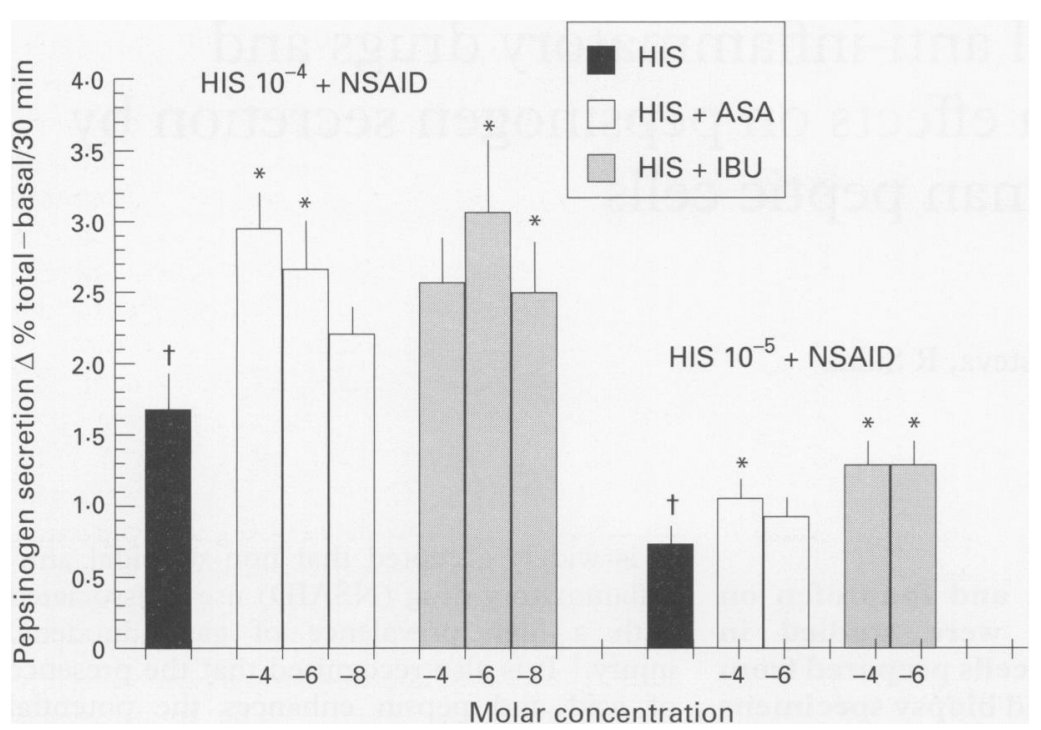

Figure 1: Effects of different concentrations of both aspirin (ASA) and ibuprofen (IBU) on two different concentrations of histamine (HIS) stimulated pepsinogen secretion from dispersed human peptic cells. Basal secretion in these experiments was $4.86(0.57) \%$ of total/30 min. $n=4-7 .{ }^{\star} p<0.05$ with respect to histamine stimulated secretion, $\dagger p<0.05$ with respect to basal secretion.

Unless otherwise stated, the standard Ringer solution contained $82.2 \mathrm{mM} \mathrm{NaCl}, 4.0 \mathrm{mM}$ $\mathrm{KCl}, 1.8 \mathrm{mM} \mathrm{CaCl}, 0.8 \mathrm{mM} \mathrm{MgCl}_{2}, 0.8$ $\mathrm{NaSO}_{4}, \quad 17.8 \mathrm{mM} \quad \mathrm{NaHCO}_{3}, \quad 0.8 \mathrm{mM}$ $\mathrm{NaH}_{2} \mathrm{PO}_{4}, 11.5 \mathrm{mM}$ glucose, and $0.2 \%$ bovine serum albumin. The medium was equilibrated with $95 \% \mathrm{O}_{2}-5 \% \mathrm{CO}_{2}$ and $\mathrm{pH}$ was adjusted to $7 \cdot 25$. $\mathrm{Ca}^{++}$low medium contained $0 \cdot 1 \mathrm{mM}$ $\mathrm{CaCl}_{2}$ and no $\mathrm{MgCl}_{2}$, and $\mathrm{Ca}$ free medium contained no $\mathrm{CaCl}_{2}$ or $\mathrm{MgCl}_{2}$.

\section{Biopsy specimens}

Gastric biopsy specimens were obtained from
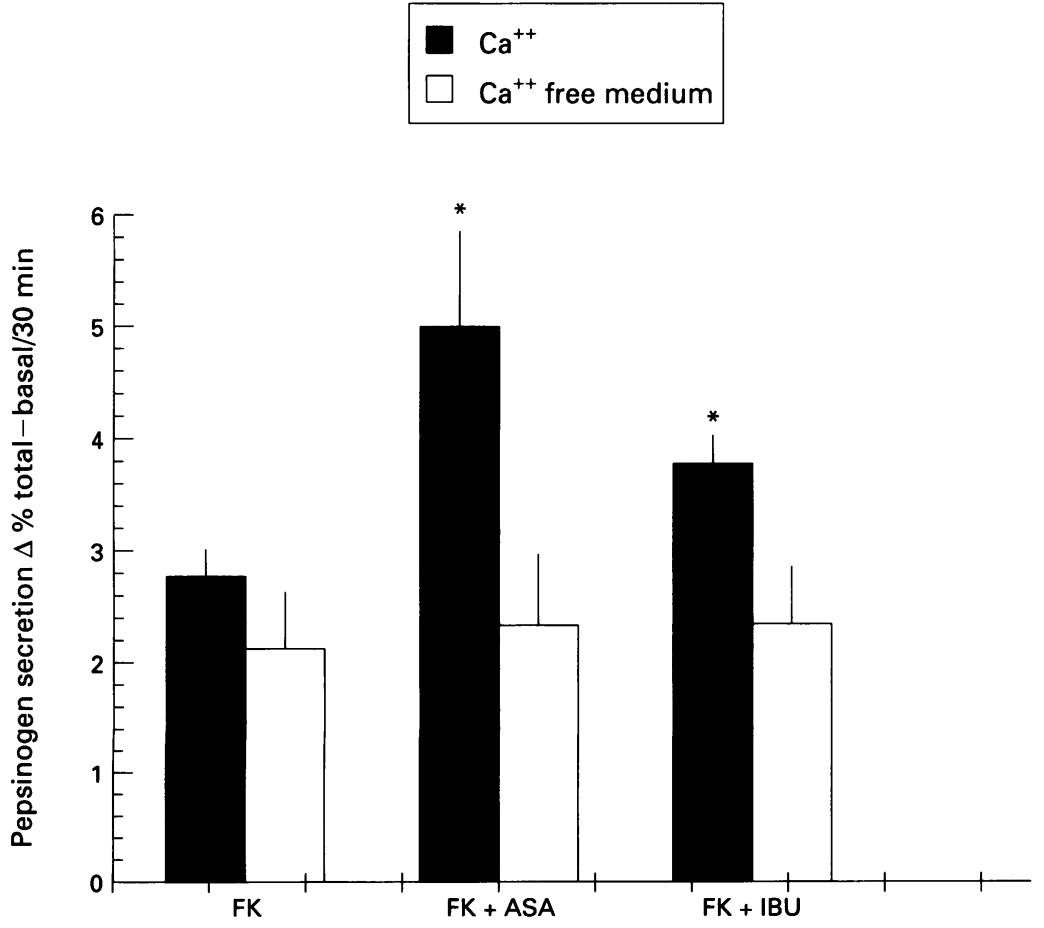

Figure 2: Effects of both aspirin $(A S A)\left(10^{-6} \mathrm{M}\right)$ and ibuprofen $(I B U)\left(10^{-4} \mathrm{M}\right)$ on forskolin $(F K)\left(10^{-5} \mathrm{M}\right)$ stimulated pepsinogen secretion from dispersed human peptic cells. Removal of extracellular calcium from the medium suppressed the potentiation effect of both drugs on forskolin stimulated pepsinogen secretion. Basal secretion in these experiments was $3.40(0.29) \%$ of total/30 min. $n=4-5 .{ }^{\star} p<0.05$ with respect to forskolin.
69 patients undergoing upper gastrointestinal endoscopy (45 men and 15 women). The mean (SEM) age of this population was $39 \cdot 11$ $(1.59)(18-61)$. In 20 of these patients the endoscopy was normal, 18 had an active duodenal ulcer, 14 a healed duodenal ulcer, nine a hiatal hernia, six oesophagitis, five duodenitis, five antritis, and two a gastric ulcer. Most of them (55 of 69) were or had recently been receiving $\mathrm{H}_{2}$ receptor antagonists, and the rest were receiving antacids or were free of any treatment. Helicobacter pylori status in the corpus of the stomach was not determined, but it was in the antrum (CLO test) in 43 of 69 patients (positive in 40). The study was approved by the Institutional Review Board and written informed consent was obtained from all patients.

\section{Cell isolation}

The method used to isolate peptic cells had been previously described elsewhere. ${ }^{13}$ In brief, eight to 10 endoscopically obtained gastric biopsy specimens (jumbo forceps) from the oxintic area were transported in Ringer's solution that had been gassed with $95 \% \mathrm{O}_{2}$ and $5 \% \mathrm{CO}_{2}$. The specimens then received a 20 minute digestion in $0.1 \%$ collagenase solution with $0 \cdot 2 \%$ trypsin inhibitor in a shaking water bath at $37^{\circ} \mathrm{C}$. This initial collagenase solution was discarded and replaced and digestion continued for 45 more minutes. The cells and glands were collected by centrifugation, resuspended in Ringer's solution without calcium and magnesium, and subjected to repetitive pipetting for several minutes. The cells were filtered through 100 $\mu \mathrm{m}$ Teflon mesh and resuspended in Ringer's solution containing calcium and magnesium. The cells were then taken up in $1 \mathrm{ml}$ of Ringer's solution and layered onto $2 \mathrm{ml} \mathrm{50 \%}$ $(\mathrm{v} / \mathrm{v})$ percoll containing isotonic HEPES buffered Ringer's solution, which contained $82.2 \mathrm{mM} \mathrm{NaCl}, 4 \mathrm{mM} \mathrm{KCl}, 1.8 \mathrm{mM} \mathrm{CaCl}_{2}$, $0.8 \mathrm{mM} \mathrm{MgCl}_{2}, 19.4 \mathrm{mM}$ HEPES, $11.5 \mathrm{mM}$ glucose, and $0.2 \%$ bovine serum albumin. The cells were then centrifuged at $14000 \mathrm{~g}$ for 20 minutes at $4^{\circ} \mathrm{C}$ (Eppendorf Centrifuge, Model 5412). After this centrifugation the bottom of the gradient containing mainly red blood cells was discarded, and the remaining cells were washed and layered again onto a $2 \mathrm{ml} \mathrm{33 \%}$ (v/v) containing isotonic HEPES buffered Ringer's solution. After another centrifugation at $14000 \mathrm{~g}$ for 10 minutes, the top of the gradient containing mainly the parietal cells was discarded and a clearly different layer at the bottom contained the chief cells. The isolated chief cells were greater than $90 \%$ pure by microscopy (haematoxylin and eosin staining procedure and periodic acid schiff reaction), and $>90 \%$ viable by trypan blue exclusion and $>89 \%$ by flow cytometry (Epics Elite, Coulter, Hialeah Fl, USA) using the fluorochromes, rhodamine 123 and propidium iodide to measure live and dead cells respectively. ${ }^{1415}$ The pepsinogen content of this layer was 100 times higher than the pepsinogen obtained from the top layer containing mainly 


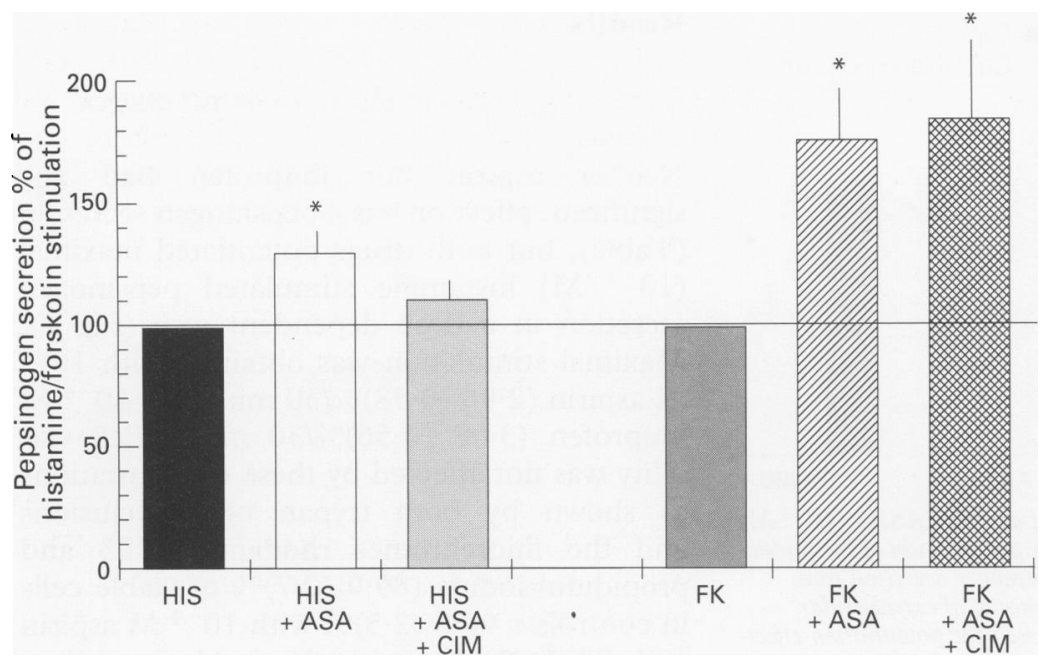

Figure 3: Effects of cimetidine (CIM) $\left(2 \times 10^{-4} \mathrm{M}\right)$ on aspirin $\left(10^{-6} \mathrm{M}\right)$ potentiation of either histamine (HIS) $\left(10^{-4} \mathrm{M}\right)$ or forskolin $(F K)\left(10^{-5} \mathrm{M}\right)$ stimulated pepsinogen secretion from dispersed human peptic cells. Results are expressed as percentage of pepsinogen secretion obtained after stimulation with either histamine or forskolin minus basal secretion and set at $100 \%$. Basal secretion for both histamine and forskolin was similar to those values expressed in previous figures. $n=3-5,{ }^{\star} p<0.05$.

parietal cells. No significant pepsinogen secretion was obtained from the top layer when stimulated with acetylcholine or cholecystokinin octapeptide.

Eight biopsy specimens from one young patient yielded about $10^{6}$ cells that were suspended in Ringer's solution under $95 \% \mathrm{O}_{2}$ $5 \% \quad \mathrm{CO}_{2}$ atmosphere and refrigerated overnight. The next morning, the cells were allowed to warm at room temperature before they were used in experiments. No experiments were performed if cell viability was lower than $89 \%$ and experiments with low total pepsinogen content were discarded.

\section{Experiments and calculations}

The warmed cells were resuspended in fresh

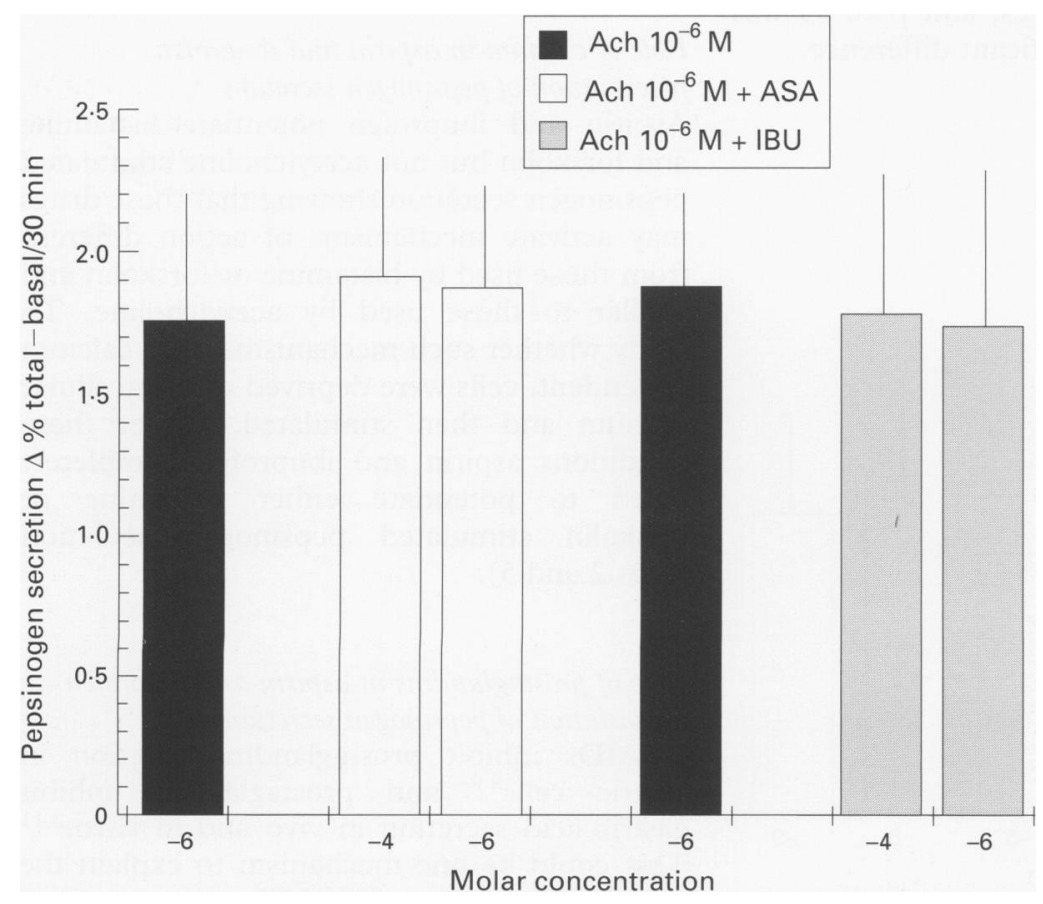

Figure 4: Effects of both aspirin (ASA) and ibuprofen (IBU) on acetylcholine (Ach) stimulated pepsinogen secretion from dispersed human peptic cells. Basal secretion in these experiments was $5 \cdot 24(0 \cdot 27) \%$ of total 30 min. $n=3-4$.
Ringer's solution and counted (haematocytometer). Aliquots of $10^{5}$ cells were then placed in $1.5 \mathrm{ml}$ polypropylene test tubes containing the appropriate agents and incubated in a shaking water bath under an atmosphere of $95 \% \quad \mathrm{O}_{2}-5 \% \quad \mathrm{CO}_{2}$ at $37^{\circ} \mathrm{C}$ for various times. In general, cells from a single patient were sufficient for 9-11 aliquots (including duplicates). If the experiment was high in number of aliquots or samples, two sets of cells from two different subjects were put together. In this case $n=4$ means eight people. The experiments were finished by centrifuging the tubes for 17 seconds at $14000 \mathrm{~g}$ and pipetting off the supernatants. An aliquot of the supernatant was assayed for pepsinogen activity using a modified Anson-Mirsky method using acid denaturated haemoglobin as the substrate as previously described. ${ }^{16}$ The mixture was incubated at $37^{\circ} \mathrm{C}$ for five hours and the reaction stopped by adding $1 \mathrm{ml}$ of $7 \%$ trichloroacetic acid solution followed by centrifugation at $13000 \mathrm{rpm}$ for five minutes. The optical absorbance of the supernatant was read at $280 \mathrm{~nm}$. Pepsinogen released into the medium was expressed as percentage of the total pepsinogen initially present in cells. Secretory responses to stimuli were calculated in the output per unit time with basal output subtracted. The mean (SEM) basal rate of pepsinogen secretion in the experiments was $0.18(0.01) \%$ of total pepsinogen content per minute. The concentrations of aspirin and ibuprofen used in these experiments are within the range that can be expected in patients who take these drugs when prescribed to treat rheumatological conditions, ${ }^{1718}$ and they do not modify optical absorbance when measuring pepsinogen activity.

In some experiments, carried out to study the role of calcium in NSAIDs on pepsinogen secretion, cells were washed once in calcium free Ringer's solutions, resuspended in calcium free Ringer's solution containing $0.5 \mathrm{mM}$ EGTA for three minutes to remove extracellular $\mathrm{Ca}^{++}$, washed again, and finally resuspended in calcium free Ringer's solution plus the drugs to be tested.

\section{Cell labelling and detection of eicosanoid production}

Synthesis of prostaglandins from endogenous cellular sources was measured by radiolabelling resuspended cells with $10 \mu \mathrm{M} 1-{ }^{14} \mathrm{C}$-arachidonic acid (New England Nuclear, Daimlertrasse, Germany) for 30 minutes. Cells were resuspended in standard Ringer's solution with $0.2 \%$ essentially fatty acid free bovine serum albumin. After incubation, the supernatant $(1 \mathrm{ml})$ was acidified with $1 \mathrm{M}$ citric acid to $\mathrm{pH} 3.0$ and injected into $\mathrm{C}_{18}$ cartridges (Sep-Pack, Millipore Iberica, Madrid) containing octadecylsilyl silica. Elution and detection of arachidonic acid metabolites have been described elsewhere. ${ }^{19}$ In brief, the cartridges were first washed with $3 \mathrm{ml}$ of acidified water $(\mathrm{pH} 3.0)$ and $3 \mathrm{ml}$ of water, then with $1 \mathrm{ml}$ of hexane for partial elution of non-polar lipids, and finally with $2 \mathrm{ml}$ of ethanol 


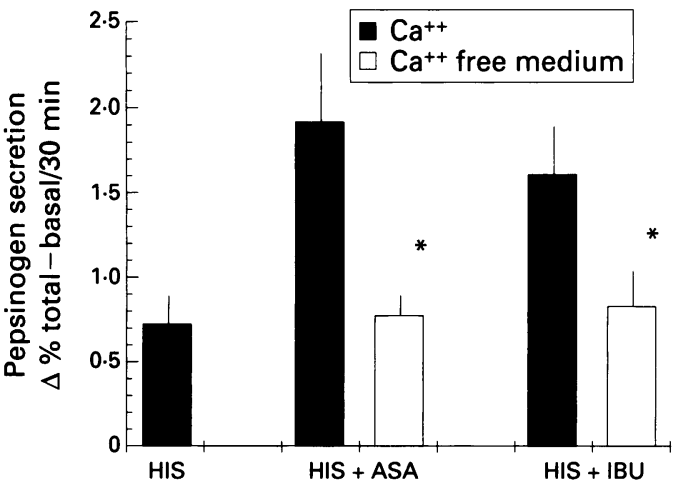

Figure 5: Calcium dependence of aspirin ( $A S A)\left(10^{-4} \mathrm{M}\right)$ and ibuprofen (IBU) $\left(10^{-6} M\right)$ potentiation of histamine (HIS) $\left(10^{-4} \mathrm{M}\right)$ stimulated pepsinogen secretion from dispersed human peptic cells. Removal of extracellular calcium from the medium suppressed the potentiation effect of aspirin and ibuprofen. Basal secretion in these experiments was $5 \cdot 19(0 \cdot 6) \%$ of total 30 min. $n=4-6$, ${ }^{\star} p<0.005$.

for elution of arachidonic acid metabolites. The ethanol fraction was evaporated to dryness under $\mathrm{N}_{2}$, then dissolved in $75 \mu \mathrm{l}$ of chloroform-methanol (2:1) and applied onto silica gel 60 thin layer chromatography plates (E Merck, Darmstadt, Germany). The plates were developed using the solvent system - ethylacetate:acetic acid:isooctane: water (110:20:50:100) - for separation of cycloxygenase products. Five $\mu \mathrm{g}$ each of authentic standards of prostaglandin $\mathrm{E}_{2}$ and $\mathrm{D}_{2}$ were also applied onto each thin layer chromatography plate, and were visualised by exposure to iodine vapour. Each band was then scraped off into scintillation vials, mixed with 10 $\mathrm{ml}$ of scintillation cocktail, and counted in a scintillation counter (Packard) after one hour.

Results are presented as mean (SEM) and the number ( $\mathrm{n}$ ) in each experiment is equal to the number of separate cell preparations. Statistical significance was determined by Student's $t$ test for unpaired values and either equal or unequal variances, and $\mathrm{p}<0.05$ was taken to represent a significant difference.

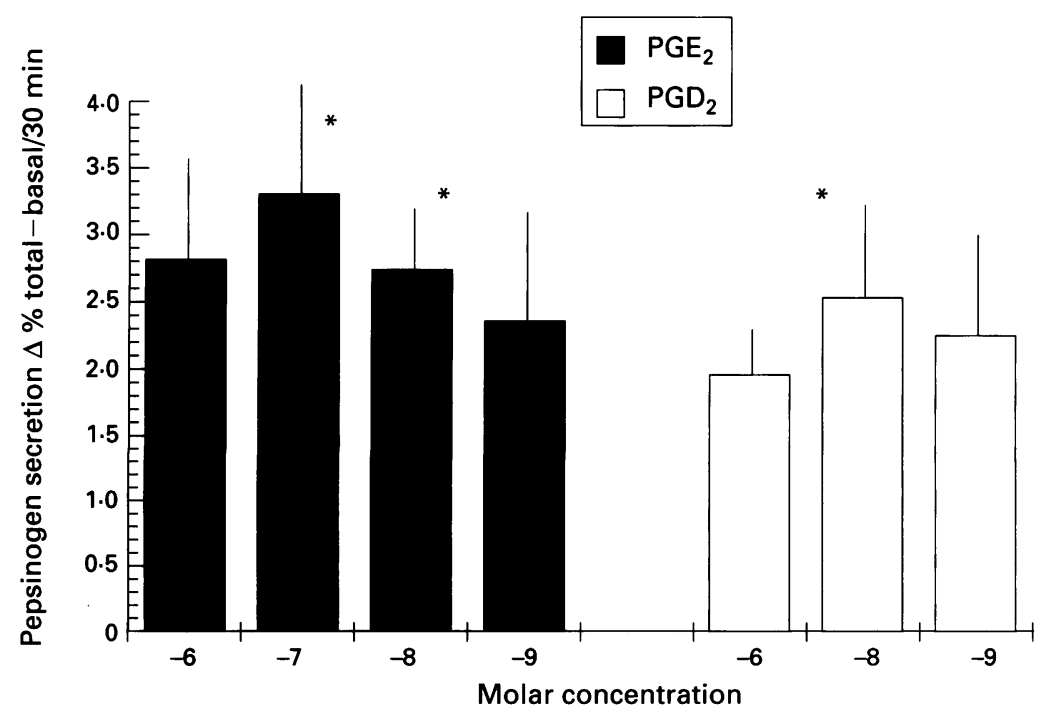

Figure 6: Prostaglandins ( $P G E_{2}$ and $P G D_{2}$ ) stimulate pepsinogen secretion from dispersed human peptic cells. Basal secretion in these experiments was $6.33(0.60) \%$ of total 30 min. $n=4-5,{ }^{\star} p<0 \cdot 05$.

\section{Results}

Effects of aspirin and ibuprofen on pepsinogen secretion

Neither aspirin nor ibuprofen had any significant effect on basal pepsinogen secretion (Table), but both drugs potentiated maximal $\left(10^{-4} \mathrm{M}\right)$ histamine stimulated pepsinogen secretion in a dose dependent way (Fig 1). Maximal stimulation was obtained with $10^{-4}$ $\mathrm{M}$ aspirin $(2.96(0.38) \% / 30 \mathrm{~min})$ and $10^{-6} \mathrm{M}$ ibuprofen $(3.08(0.56) \% / 30 \mathrm{~min})$. Cell viability was not affected by these concentrations as shown by both trypan blue exclusions and the fluorchromes rhodamine 123 and propidium iodide $(89.9(2.7) \%$ of viable cells in controls $v 90.8(2.5) \%$ with $10^{-4} \mathrm{M}$ aspirin and $90.8(2 \cdot 7) \%$ with $10^{-6} \mathrm{M}$ ibuprofen; $\mathrm{n}=5$ ). Potentiation of pepsinogen secretion was also seen when peptic cells were prestimulated with lower doses of histamine $\left(10^{-5} \mathrm{M}\right)$ and reinforces the physiological significance of these effects. Like histamine, pepsinogen secretion stimulated by forskolin $\left(10^{-5} \mathrm{M}\right)$, an intracellular secretagogue that activates the catalytic subunit of adenylate cyclase, was also potentiated by both aspirin and ibuprofen (Fig 2). Cimetidine $\left(2 \times 10^{-4}\right.$ M) blocked aspirin potentiation of histamine stimulated pepsinogen secretion but did not inhibit significantly aspirin effects on forskolin stimulated pepsinogen secretion (Fig 3), showing that cimetidine inhibited histamine stimulation in itself rather than the potentiation of aspirin.

Aspirin and ibuprofen $\left(10^{-4}-10^{-8} \mathrm{M}\right)$ failed to potentiate acetylcholine stimulated pepsinogen secretion suggesting that the potentiating effect of these two drugs may be mediated by mechanisms that share some intracellular pathway (for example, $\mathrm{Ca}^{++}$) but do not change muscarinic related responses (Fig 4).

\section{Role of calcium in aspirin and ibuprofen potentiation of pepsinogen secretion}

Aspirin and ibuprofen potentiate histamine and forskolin but not acetylcholine stimulated pepsinogen secretion showing that these drugs may activate mechanisms of action different from those used by histamine or forskolin and similar to those used by acetylcholine. To study whether such mechanisms were calcium dependent, cells were deprived of extracellular calcium and then stimulated. Under these conditions aspirin and ibuprofen completely failed to potentiate either histamine or forskolin stimulated pepsinogen secretion (Figs 2 and 5).

Role of prostaglandins in aspirin and ibuprofen potentiation of pepsinogen secretion

NSAIDs inhibit prostaglandin secretion in gastric cells ${ }^{89}$ and prostaglandins inhibit gastric acid secretion in vivo and in vitro. ${ }^{211}$ This could be one mechanism to explain the potentiation effects of NSAIDs on pepsinogen secretion. In our system, we have seen that the addition of $10^{-4} \mathrm{M}$ aspirin inhibited 


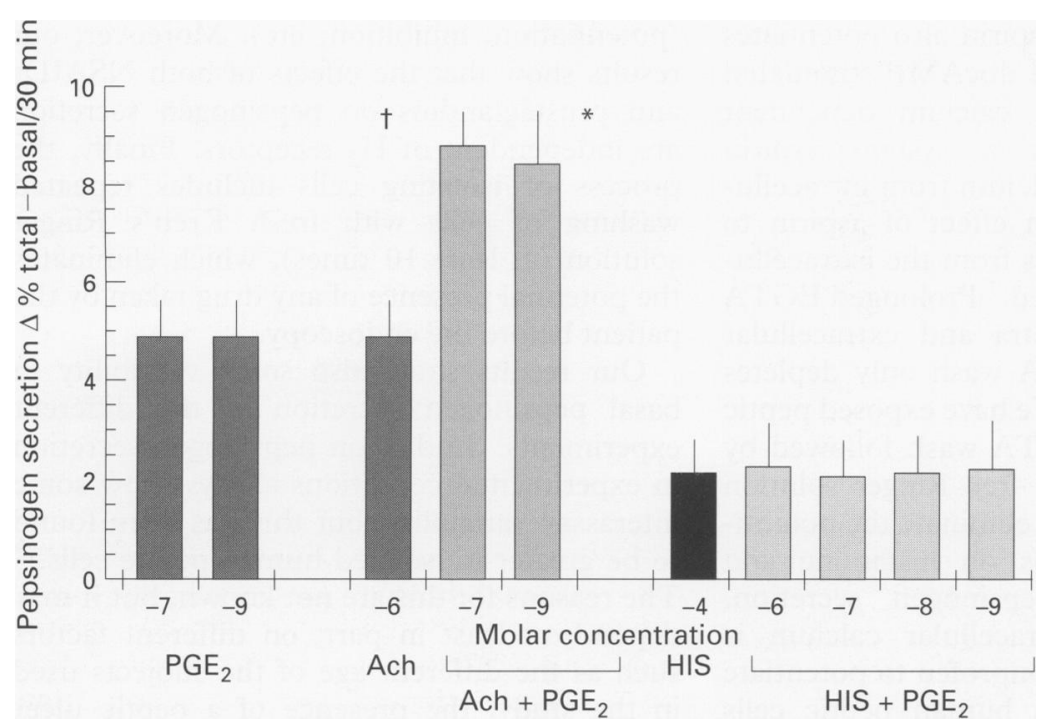

Figure 7: Prostaglandin (PGE ) stimulation of pepsinogen secretion from dispersed human peptic cells is in addition to that obtained with acetylcholine (Ach), but it is not to pepsinogen secretion obtained with histamine (HIS) stimulation. Basal secretion in these experiments was $5.75(1 \cdot 1) \%$ of total/30 min. $n=4,{ }^{\star} p<0.05, \dagger p<0.01$.

endogenous production of both radiolabelled $\mathrm{PGE}_{2}$ and $\mathrm{PGD}_{2}$ by peptic cells $\left(\mathrm{PGE}_{2}=3930\right.$ (135) $\mathrm{cpm} / \mu \mathrm{g}$ protein $v 1115(236)^{\star}$ with aspirin; $\mathrm{PGD}_{2}=4194(486) \mathrm{cpm} / \mu \mathrm{g}$ protein $v$ $1483(596)^{\star}$ with aspirin; $\left.n=3-5 ;{ }^{\star} \mathrm{p}<0.05\right)$. In contrast with published data, we found that exogenous $\mathrm{PGE}_{2}$ and $\mathrm{PGD}_{2}$ both induced a dose dependent increase in pepsinogen secretion in human peptic cells (Fig 6). Maximal secretion was obtained at $10^{-7} \mathrm{M}$ $\mathrm{PGE}_{2}(3.30(1 \cdot 11) \% / 30 \mathrm{~min})$ and $10^{-8} \mathrm{M}$ with $\mathrm{PGD}_{2} \quad(2.51 \quad(0.8) \% / 30 \mathrm{~min})$. Pepsinogen secretion induced by prostaglandins was in addition to that induced by acetylcholine. However, prostaglandins failed to increase histamine stimulated pepsinogen secretion (Fig 7) and did not modify aspirin and ibuprofen potentiation of histamine stimulated pepsinogen secretion either (Fig 8).

\section{Discussion}

Aspirin and other NSAIDs have been reported to increase basal or histamine stimulated acid secretion, or both in vivo and also in vitro in

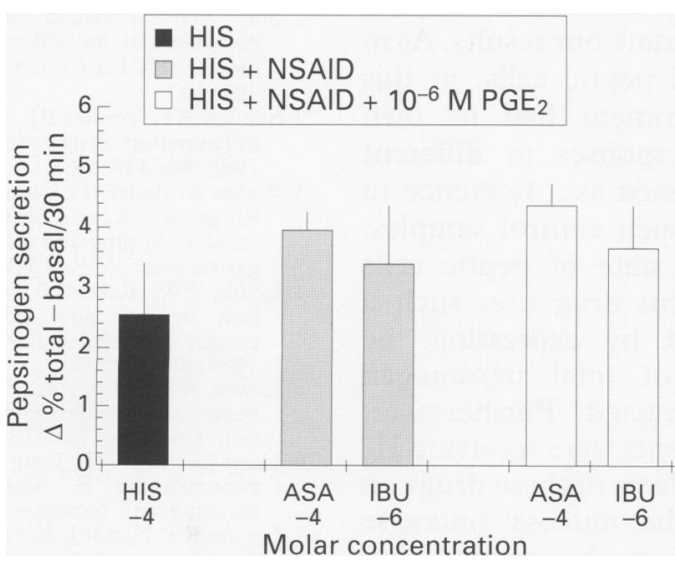

Figure 8: Exogenous prostaglandin ( $\left.P G E_{2}\right)$ addition does not affect aspirin ( $A S A$ ) and ibuprofen (IBU) potentiation of histamine (HIS) stimulation of pepsinogen secretion from dispersed human peptic cells. Basal secretion in these experiments was $4 \cdot 80(0 \cdot 60) \%$ of total $30 \mathrm{~min} . n=3$. humans and different animal models. ${ }^{7-11}$ These effects have suggested that enhanced gastric secretion by NSAIDs could be a factor in the pathogenesis of NSAID induced gastroduodenal injury. ${ }^{7-10}$ Species differences have been reported on the actions of NSAIDs in rabbits, frogs, and humans on parietal cells ${ }^{61120-22}$ and show that data from one species cannot be fully extrapolated to others (for example, humans). ${ }^{14}$

Unlike gastric acid secretion, there are almost no data on the potential effects of NSAIDs on pepsinogen secretion. A report from Ohe et al ${ }^{23}$ showed that aspirin increased the ratio of alkali-labile to total pepsinogen in the homogenates of gastric mucosa in rats and considered that activated pepsinogen was an essential step in ulcer formation by the hydrogen ion back diffusion. By using an 'in vitro' model of isolated human peptic cells, we now provide evidence for the first time that both aspirin and ibuprofen (two widely used NSAIDs) potentiate secretagogue stimulated pepsinogen secretion in humans. The potentiation of histamine stimulated pepsinogen secretion was seen at concentrations of both aspirin and ibuprofen that are commonly reached in plasma of patients who regularly used these drugs. ${ }^{1718}$ Furthermore, the potentiation effect was also seen on different histamine concentrations $\left(10^{-4}-10^{-6} \mathrm{M}\right)$ that are in the range required for maximum acid stimulated in the vascularly perfused rat stomach. ${ }^{24}$

We have also explored the mechanisms by which aspirin and ibuprofen potentiate stimulated pepsinogen secretion by human peptic cells. Receptor and signal transduction pathway studies have clearly defined two sets of pepsinogen secretagogues: (a) those that activate adenylyl cyclase (for example, histamine, forskolin, vasoactive intestinal peptide, etc) and stimulate intracellular cAMP and (b) calcium mediated secretagogues (for example, acetylcholine, cholecystokinin, gastrin, etc); these agents interact with receptors in chief cells and result in the activation of enzymes that mediate phospholipid hydrolysis, release of calcium from intracellular stores, and the activation of calcium-calmodulin dependent protein kinases. ${ }^{25-27}$ Aspirin and ibuprofen did not seem to potentiate pepsinogen secretion by affecting the adenylate cyclase/cAMP system or the $\mathrm{H}_{2}$ receptor. Cimetidine inhibited the potentiation of histamine stimulated pepsinogen secretion by these drugs but failed to block the potentiation effect on forskolin stimulated pepsinogen secretion. Because forskolin activates the catalytic subunit of adenylate cyclase intracellularly, these results suggest a regulatory role for aspirin and ibuprofen in conjunction with secretagogues distal to the site of the catalytic subunit of adenylate cyclase activation. On the other hand, aspirin and ibuprofen effects on pepsinogen secretion seem dependent on extracellular calcium, as these two drugs failed to potentiate either histamine or forskolin stimulated pepsinogen secretion when extracellular calcium was removed from the media. 
In rabbit parietal cells aspirin also potentiates histamine, forskolin, and dbcAMP stimulated aminopyrine uptake by calcium dependent mechanisms. ${ }^{7}$ In such a system aspirin increases intracellular calcium from intracellular sources, although an effect of aspirin to refill internal $\mathrm{Ca}^{++}$stores from the extracellular space was not excluded. ${ }^{7}$ Prolonged EGTA washes deplete both intra and extracellular $\mathrm{Ca}^{++}$and a brief EGTA wash only depletes extracellular $\mathrm{Ca}^{++} .728 \mathrm{We}$ have exposed peptic cells only to a brief EGTA wash followed by incubation in a calcium free Ringer solution and this was sufficient to eliminate the potentiation effect of NSAIDs on histamine and forskolin stimulated pepsinogen secretion. This suggests that extracellular calcium is needed for aspirin and ibuprofen to potentiate pepsinogen secretion in human peptic cells probably by refilling intracellular calcium stores. Furthermore, both aspirin and ibuprofen failed to potentiate acetylcholine stimulated pepsinogen secretion, a natural calcium dependent secretagogue. It is possible that intracellular calcium mobilisation by acetylcholine is potent enough to prevent further calcium increase by NSAIDs.

By finding that exogenous prostaglandins actually stimulated peptic cells, we ruled out a prostaglandin mechanism by which aspirin and other NSAIDs might potentiate pepsinogen secretion. ${ }^{78}$ Furthermore, this increase was in addition to that produced by acetylcholine suggesting that prostaglandins and acetylcholine act through independent pathways. Previous reports had already shown that prostaglandin effects on chief cells from dogs and guinea pigs were mediated by cAMP. ${ }^{29} 30$ We have confirmed this in our system because the exogenous addition of prostaglandin $\mathrm{E}_{2}$ to histamine stimulated pepsinogen secretion was not different to that obtained with histamine alone. Furthermore, aspirin potentiation of histamine stimulated pepsinogen secretion was neither inhibited nor potentiated by the addition of exogenous prostaglandin $\mathrm{E}_{2}$.

By using patient material it can be questioned whether longterm drug use may disturb the responsiveness of the mucosa (for example, $\mathrm{H}_{2}$ receptor antagonists used in most of our patients). However, we think that such a possibility does not invalidate our results. As in most studies of isolated peptic cells, in this work each single experiment had its own control samples and responses to different stimuli are always expressed as a reference to the values obtained in such control samples. Therefore, if the basal state of peptic cells was changed by longterm drug use, such a difference is eliminated by expressing the results as percentage of total pepsinogen content and basal subtracted. Furthermore, because most of our patients were receiving $\mathrm{H}_{2}$ blockers, the potential effects of these drugs on the responsiveness of the mucosa (increase or decrease secretion to histamine, etc) were present in all samples of a particular experiment and probably did not affect the main effect of the drug tested (NSAID, prostaglandins, etc) in our experiments (potentiation, inhibition, etc). Moreover, our results show that the effects of both NSAIDs and prostaglandins on pepsinogen secretion are independent of $\mathrm{H}_{2}$ receptors. Finally, the process of isolating cells includes repeated washing of cells with fresh Kreb's Ringer solution (at least 10 times), which eliminates the potential presence of any drug taken by the patient before the endoscopy.

Our results show also some variability in basal pepsinogen secretion in the different experiments. Studies on pepsinogen secretion in experimental conditions always show some interassay variability, but this has been found to be greater in isolated human peptic cells. ${ }^{13}$ The reasons for this are not known, but it may depend, at least in part, on different factors such as the different age of the subjects used in the study, the presence of a peptic ulcer disease, the presence of Helicobacter pylori infection, etc. In this way, serum pepsinogen has been found to decrease in ulcer patients after $H$ pylori eradication ${ }^{31}$ and in vitro sonicated preparations of $H$ pylori increased pepsinogen secretion from isolated rabbit gastric glands. ${ }^{32}$ However, $H$ pylori had no effect in isolated guinea pig gastric glands. ${ }^{33}$ Whether $H$ pylori affects pepsinogen secretion of human peptic cells, or the response of these cells to natural agonists (acetylcholine, histamine, prostaglandins), and whether this infection or any other factor are responsible for the variability in basal pepsinogen secretion from isolated human peptic cells warrant further studies.

In conclusion, our data show that pharmacological doses of two of the most widely used NSAIDs (aspirin and ibuprofen) potentiate secretagogues stimulated pepsinogen secretion from dispersed human peptic cells and this might be an additional mechanism of NSAID induced gastric mucosal injury in humans. The potentiation effect of these drugs is calcium dependent, independent of endogenous prostaglandin inhibition, and may be mediated in peptic cells at a post-receptor site.

This study was supported by a grant from the Asociación para Investigaciones Grastoenterológicas de la Provincia de Zaragoza. The authors thank Professor Basil I Hirschowitz for critical discussion and review of the manuscript.

1 Soll AH, Weinstein WN, Kurata J, McCarthy D. Nonsteroidal antiinflammatory drugs and peptic ulcer disease (UCLA Conference). Ann Intern Med 1991; 114: 307-19.

2 Schoen RT, Vender RJ. Mechanisms of nonsteroidal antiinflammatory drug-induced gastric damage. Am $\mathcal{F}$ Physiol inflammatory drug

3 Walan A, Bader JP, Classen M, Lamers CBH, Piper DW, Rutgersson $\mathrm{K}$, et al. Effect of omeprazole and ranitidine on ulcer healing and relapse rates in patients with benign gastric ulcer. N Engl f Med 1989; 320: 69-75.

4 Leung FW, Robert A, Guth P. Gastric mucosal blood flow in rats after administration of 16,16-dimethyl prostaglandin E2 at a cytoprotective dose. Gastroenterology 1985; 88: 1948-53.

5 Levine RA, Schwartzel EH Jr. Effect of indomethacin on basal and histamine-stimulated human gastric acid secretion. Gut 1984; 25: 718-22.

6 Hunt JN, Smith JL, Jiang CL, Kessler L. Effect of synthetic prostaglandin $\mathrm{E}_{1}$ analog on aspirin-induced gastric

7 Levine RA, Nandi J, King RL. Aspirin potentiates prestimulated acid secretion and mobilizes intracellular calcium
uning ulated acid secretion and mobilizes intracellular calciur
in rabbit parietal cells. $\mathcal{f}$ Clin Invest 1990; 86: 400-8.

8 Levine RA, Nandi J, King RL. Nonsalicylate nonsteroidal antiinflammatory drugs augment prestimulated acid secretion in rabbit parietal cells. Investigation of th mechanisms of action. Gastroenterology 1991; 101 756-65. 
9 Murthy UK, Levine RA. Aspirin induces morphological transformation to the secretory state in isolated rabbit parietal cells. Gastroenterology 1991; 101: 404-9.

10 Reeves J, Stables R. Effect of indomethacin, piroxican and selected prostanoids on gastric acid secretion by the rat isolated gastric mucosa. Br f Pharmacol 1985; 86: rat isolated $677-84$.

11 Jaramillo E, Mardh S, Gréen K, Persson B, Rubio C. The effect of arachidonic acid and its metabolites on acid production in isolated human parietal cells. Scand $\mathcal{f}$ Gastroenterol 1989; 24: 1231-7.

12 Hirschowitz BI. Pepsin in the pathogenesis of peptic ulceration. In: Halter F, Garner A, Tytgat GNJ, eds. Falk Symposium 59. Mechanisms of peptic ulcer healing. Dordrecht, The Netherlands: Kluwer Academic, 1991: 183-94.

13 Lanas AI, Anderson JW, Uemura N, Hirschowitz BI Effects of cholinergic, histaminergic and peptidergic stimulation on pepsinogen secretion by isolated human peptic ulation on pepsinogen secretion by isolated hum

14 Johnson LU, Walsh ML, Bokus BJ, Chen LB. Monitoring of relative mithocondrial membrane potential in living cells by fluorescence microscopy. F Cell Biol 1981; 83: 526-35.

15 Crissman HP, Egmond JV, Holdrinet RS, Pennings JV, Haanen C. Simplified method for DNA and protein staining of human hematopoietic cell samples. Cytometry 1981; 2: 59-62.

16 Matsumoto K, Dickinson KEJ, Anderson W, Hirschowitz BI. Pepsinogen secretion from perifused frog peptic B1. Pepsinogen secretion from perifused frog peptic glands: rapid transiets detected
assay. Life Sci 1988; 42: 1237-44.

17 Mandelli M, Tognoni $G$. Monitoring plasma concentration of salicylate. Clin Pharmacokinet 1980; 5: 424-40.

18 Geisslinger G, Schuster O, Stock KP, Loew D, Bach GL, Brune K. Pharmacokinetics of $S(+)$ - and $R(-)$-ibuprofen in volunteers and first clinical experience of $S(+)$-ibuprofen in rheumatoid arthritis. Eur f Clin Pharmacol 1990; 38: 493-7.

19 ElAttar TMA, Lin HS, Platt RD. Effect of effervescent buffered aspirin on prostaglandin synthesis by human gingival fibroblasts. Prostaglandins Leukot Med 1987; 29: gival fib 47 .

20 Seeger AJM, Jager LP, VanNoordwijk. Effects of phenacetin, paracetamol and caffeine on the erosive activity of acetylsalicylic acid in the rat stomach: dose-response relationships, time course of erosion development and effects on acid secretion. $\mathcal{F}$ Pharm Pharmacol 1979; 31: $840-8$.
21 Shea-Donohue T, Steel L, Montcalm-Mazzilli E, Dubois A. Aspirin-induced changes in gastric function: role of endogenous prostaglandins and mucosal damage. Gastroenterology 1990; 98: 284-92.

22 Rowe PH, Starlinguer MJ, Kasdon E, Marrone G, Silen W. Effect of simulated systemic administration of aspirin, salicylate and indomethacin on amphibian gastric mucosa. icylate and indomethacin on amp

23 Ohe K, Yokoya H, Kitaura T, Kunita T, Miyoshi A Increase in pepsin content in gastric mucosa during the course of aspirin- and taurocholate-induced gastric ulceration in rats. Dig Dis Sci 1980; 25: 849-56.

24 Sandvik AK, Waldum HL, Kleveland PM, Schulze SB. Gastrin produces an immediate and dose-dependent histamine release preceding acid secretion in the totally isolated, vascularly perfused rat stomach. Scand 7 Gastroenterol 1987; 22: 803-8.

25 Raufman JP. Gastric chief cells: receptors and signal-transduction mechanisms. Gastroenterology 1992; 102: duction

26 Defize J, Meuwissen GM. Pepsinogens: an update of biochemical, physiological and clinical aspects. $f$ Pediat Gastroenterol Nutr 1987; 6: 493-508.

27 Basson MD, Modlin IM. Pepsinogen: biological and pathophysiologic significance. $\mathcal{F}$ Surg Res 1988; 44 82-97.

28 Hirschowitz BI, Uemura N, Matsumoto $\mathrm{H}$, Dickinson KEJ. The role of $\mathrm{Ca}^{++}$in the time-dependent pepsinogen secretion of frog oesophageal peptic glands stimulated by bombesin. Acta Physiol Scand 1990; 140: 401-12.

29 Defize J, Hunt RH. Effect of hydrochloric acid and prostaglandins on pepsinogen synthesis and secretion in canine gast $774-81$.

30 Raufman J-P, Cosowsky L. Relation of prostaglandininduced increases in cellular cAMP to stimulation of pepsinogen secretion from dispersed chief cells. $\mathcal{F}$ Cell Physiol 1987; 132: 137-42.

31 Chittajallu RS, Dorian CA, McColl KEL. Serum pepsinogen $\mathrm{I}$ in duodenal ulcer-effect of eradication of $\mathrm{H}$ pylori and correlation with serum gastrin and antral gastritis. Gut 1990; 31: A1199.

32 Cave TR, Cave DR. Helicobacter pylori stimulates pepsin secretion from isolated rabbit gastric glands. Scand $\mathcal{f}$ Gastroenterol 1991; 26 (suppl 181): 9-14.

33 Rademaker JW, Hunt RH. Helicobacter pylori and gastric acid secretion: the ulcer link? Scand $\mathcal{f}$ Gastroenterol 1991; 26 (suppl 187): 71-7. 